\title{
Alterations of insulin sensitivity by the implantation of 3T3-L1 cells in nude mice. A role for TNF- $\alpha$ ?
}

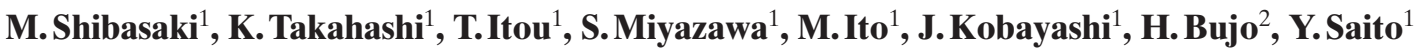 \\ ${ }^{1}$ Department of Clinical Cell Biology, Graduate School of Medicine, Chiba University, Chiba, Japan \\ ${ }^{2}$ Department of Genome Research and Clinical Application, Graduate School of Medicine, Chiba University, Chiba, Japan
}

\begin{abstract}
Aims/hypothesis. Visceral adipocytes have different functions than those from the subcutaneous fat area. These differences could contribute to the pathological significance of excessive visceral fat accumulation for accompanying insulin resistance and hyperinsulinaemia. This study addresses this hypothesis and describes a unique method to clarify whether the functional differences between visceral and subcutaneous adipocytes depend on their anatomical location.

Methods. 3T3-L1 cells or TNF- $\alpha$ overexpressing $\mathrm{CHO}$ cells were implanted into subcutaneous fat area or mesenteric area as visceral fat area in athymic mice of $B A L B / C$ strain. Then, serum insulin, glucose, TNF- $\alpha$, and several markers of lipid metabolism were measured in the fasting condition. OGTT was also analysed.
\end{abstract}

Results. During the course of glucose loading, the mice which had 3T3-L1 cells implanted into mesen- teric area but not into subcutaneous fat area showed remarkably increased serum insulin and TMF- $\alpha$ concentrations, compared to the control mice. Moreover, serum insulin concentrations of the mice, implanted with TNF- $\alpha$ overexpressing cells into subcutaneous fat area, were apparently higher than that of control mice.

Conclusion/interpretation. This method of implanting adipose cells into subcutaneous or visceral fat area showed high TNF- $\alpha$ concentration and insulin resistance by the adipose cells in visceral area of nude mice. Furthermore, we found that the functional significance of visceral fat accumulation for TNF- $\alpha$-induced insulin resistance is partly caused by the interaction of adipocytes with surrounding conditions in mesenteric area. [Diabetologia (2002) 45:518-526]

Keywords Fat distribution, 3T3-L1 cells, lipoprotein lipase, TNF- $\alpha$, insulin sensitivity, obesity.
Visceral fat accumulation is known to be a clinical index for insulin resistance related to obesity [1-3]. Patients with excessive accumulation of visceral fat frequently suffered from metabolic disorders, such as hyperlipidaemia, hypertension and glucose intoler-

Received: 15 February 2001 and in revised form: 21 December 2001

Corresponding author: K. Takahashi, Department of Clinical Cell Biology, Graduate School of Medicine, Chiba University, Chiba, Japan, e-mail: kazuot@intmed02.chiba-u.ac.jp Abbreviations: hTNF- $\alpha$, human TNF- $\alpha$; FBS, fetal bovine serum; TC, total cholesterol; TG, triglycerides; HDL-C, high density lipoprotein cholesterol; LPL, lipoprotein lipase; $\mathrm{CHO}$, Chinese Hamster Ovary ance [4-6]. However, molecular mechanisms for the pathogenesis of obesity-accompanied metabolic disorders are not clear. So far, it has been clarified that adipose cells in visceral areas have different functions both in vivo and in vitro from the cells in subcutaneous areas, and these differences might contribute the pathological significance of visceral fat accumulation for accompanying insulin resistance and hyperinsulinaemia [7]. We have reported that patients with excessive visceral fat accumulation show delayed postprandial triglyceride (TG) metabolism compared to normal subjects, and the disturbed metabolism is, at least in part, caused by reduced lipoprotein lipase (LPL) mass and activity in their sera $[8,9]$. In accordance with the clinical observations, model rats for 
excessive visceral fat accumulation revealed negative correlation between the serum concentration of insulin or TNF- $\alpha$ and the LPL mRNA expression in muscle and subcutaneous fat [10]. These in vivo results strongly suggest that visceral fat secretes cytokines such as TNF- $\alpha$, and that this mechanism is the cause of insulin resistance in human beings as well as rodents.

Cultured adipose cells from visceral and subcutaneous fat have different activities of proliferation and lipid metabolism [11]. Furthermore, the different gene expression of visceral and subcutaneous fat in vivo has been clarified, and genes abundantly expressed in visceral fat have been identified using subtraction cloning [12,13]. Although the different gene expressions and cell properties of visceral and subcutaneous fat have been observed, it is not clear why the adipose cells in a visceral area have a different function and gene expression from those in a subcutaneous area.

Recently, subcutaneously implanted adipose tissue has been reported to improve the glucose intolerance accompanied with lipoatrophic mice [14]. Subcutaneously implanted preadipocytes are able to secrete leptin, although not in vitro [15]. These observations suggest the adipose cells interact with the surrounding cells and tissues, and the functions of adipose cells might be modified by the stimuli from their surroundings. In this study, we clarified the molecular mechanism of different cell properties. The implantation of exogenous cells, in particular adipose cells, into nude mice modified the metabolic status associated with insulin resistance. Furthermore, these results using implantation methods indicate that TNF- $\alpha$ causes the metabolic disturbance associated with decreased insulin sensitivity in mice.

\section{Materials and methods}

Materials. DMEM, FBS, G418 and trypsin were obtained from Invitrogen Japan K. K. (Tokyo, Japan). PBS was from Nissui Pharmaceuticals (Tokyo, Japan).

Preadipocytes culture. 3T3-L1 cells, an established preadipocyte cell line, was obtained from the American Type Culture Collection (Manassas, Va, USA) and cultured in Dulbecco's modified Eagle's medium (DMEM) containing $10 \%$ FBS at $37^{\circ} \mathrm{C}$ in a $5 \% \mathrm{CO}_{2}$ incubator.

Generation of human TNF- $\alpha$ overexpressing CHO cells. Human TNF- $\alpha$ cDNA was obtained by polymerase chain reaction from human placenta cDNA library using specific oligonucleotide primers. The cDNA fragment was subcloned into pcDNA3.1myc (Invitrogen, Japan K.K.) and sequenced. This plasmid is the expression vector for suffered protein tagged with myc epitope at carboxyl-terminus. The plasmids were transfected into $\mathrm{CHO}$ cells using lipofectAMINE reagent (Invitrogen Japan K.K.). The cells stably expressing hTNF- $\alpha$ were selected with G418 at the concentration of $0.5 \mathrm{mg} / \mathrm{ml}$ and subcloned. The hTNF- $\alpha$ overexpressing $\mathrm{CHO}$ cell clones were cultured in DMEM supplemented with $10 \%$ FBS.
Cell transplantation. The 3T3-L1 preadipocytes were grown to near confluence, trypsinised and suspended in DMEM with $10 \%$ FBS. After centrifugation, cell pellets were resuspended in PBS and injected with the amounts of $1 \times 10^{7}$ cells $(500 \mu \mathrm{l})$ through $22 \mathrm{G}$ needles into the mesenteric area close to the small intestine or subcutaneous fat area of nude mice (athymic $\mathrm{BALB} / \mathrm{C}$ strain) under anaesthetic. Mice were housed in micro-isolator cages under specific pathogen-free conditions during the whole experiment. Each week after injection, body weight was measured. Blood samples were also collected in the fasting condition each week after implantation. Four weeks after 3T3-L1 cell implantation, an OGTT was performed. Then, the mice were killed by cervical dislocation before implanted mesenteric or subcutaneous adipose tissue area was collected. The hTNF- $\alpha$ overexpressing $\mathrm{CHO}$ cells were also injected with the amounts of $1 \times 10^{7}$ cells $(500 \mu \mathrm{l})$ in mesenteric or subcutaneous area of the mice under the same conditions described above. Every week after injection, blood samples were collected. OGTT was performed at four weeks after transplantation.

Serum samples. Blood samples were obtained from retro-orbital venous plexus of the mice which had fasted over $16 \mathrm{~h}$. Serum samples were immediately prepared by centrifugation at $1500 \mathrm{~g}$ for $15 \mathrm{~min}$ at $4{ }^{\circ} \mathrm{C}$. Serum glucose, TC, TG, and high density lipoprotein cholesterol (HDL-C) were measured with commercial kits (Wako chemicals, Osaka, Japan). Serum insulin was detected by ELISA kit (Morinaga, Yokohama, Japan). Human and mouse TNF- $\alpha$ were also determined by an enzyme-linked immunosorbent assay (BioSource International, Calif., USA).

Oral glucose tolerance test. Oral glucose tolerance test was performed on conscious mice after a $16 \mathrm{~h}$ fast. The test was done by orally administrated glucose ( $2 \mathrm{mg}$ per g body weight) and measurement of blood glucose and insulin at 15 and $30 \mathrm{~min}$ after loading.

LPL mass and activity. Post-heparin plasma was obtained $10 \mathrm{~min}$ after intravenous injection of heparin at a dose of $50 \mathrm{mU}$ per g of body weight. The lipoprotein lipase mass was determined by ELISA and its activity was determined using Triton X-100 emulsified triolein as already described [8].

Histological analysis of implanted tissues. Four weeks after implantation with 3T3-L1 cell, the mice were killed by cervical dislocation before the implanted mesenteric or subcutaneous fat area was collected. For light microscopic analysis, the tissues from implanted mesenteric or subcutaneous fat area were paraffin-embedded after $24 \mathrm{~h}$ of fixation in neutral-buffered formaldehyde. Four- to six- $\mu \mathrm{m}$ tissue sections were stained with hematoxylin and eosin for histological analysis.

Reverse transcription-polymerase chain reaction. Four weeks after implantation with 3T3-L1 cell, the mice were killed by cervical dislocation before mesenteric or subcutaneous fat area or femoral muscle was collected. Total RNA was isolated with an RNA extraction kit (Qiagen K.K., Tokyo, Japan). To evaluate the contents of TNF- $\alpha$ expression, $2.0 \mu \mathrm{g}$ of total RNA was amplified by OneStep RT-PCR kit (Qiagen K.K.) using the specific primers. The PCR products were run on $2.0 \%$ agarose and stained with ethidium bromide. The relative signal intensities of the PCR products were determined with luminescent image analyser LAS-1000 (Fuji Photo Film, Tokyo, Japan). mRNA amounts were normalised to levels of beta-actin mRNA, which served as endogenous standard. 

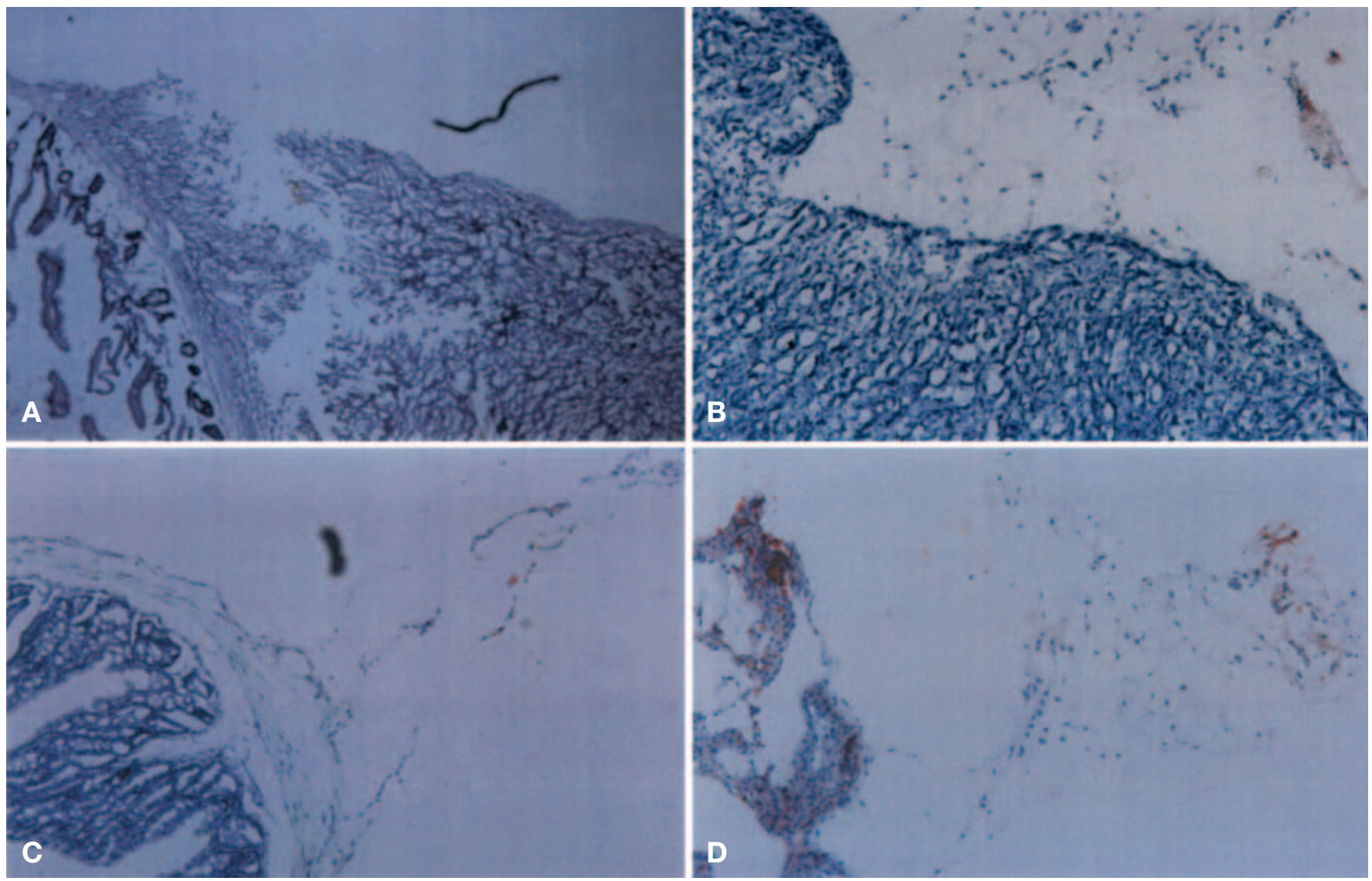

Fig. 1. Light microscopic findings of thick pad derived from implanted preadipocytes in mesenteric and subcutaneous fat area. Four weeks after implantation with 3T3-L1 cells, the implanted mesenteric or subcutaneous fat area was collected. Tissue sections were stained with hematoxylin and eosin. A Mesenteric area injected with 3T3-L1 cells. B Subcutaneous fat area injected with 3T3-L1 cells. C Mesenteric area injected with PBS alone. D Subcutaneous fat area injected with PBS alone

The primers. Primers synthesised for TNF- $\alpha$ were 5' GGCAGGTCTACTTTGGAGTCATTGC 3' and 5' ACATTCGAGGCTCCAGTGAATTC GG 3' according to known cDNA sequence. Primers for beta-actin were 5' TGGAATCCTGTGGCATCCATGAAAC 3' and 5' TAAAACGCAGCTCAGTAACAGTCCG 3'.

Statistical analysis. Statistical analysis was performed with $t$ test. All the results reported herein were confirmed by repeating the experiments with different occasions.

\section{Results}

The effects of implantation of 3T3-L1 preadipocytes into the mesenteric or subcutaneous area of nude mice. We implanted the 3T3-L1 preadipocytes into mesenteric and subcutaneous areas in which cell cluster is not usually observed in nude mice. Thickened pad formation was found in mesenteric area in which preadipocytes were injected. Histological findings at four weeks after implantation clearly showed cell cluster formation in mesenteric area (Fig. 1A and C). The 3T3-L1 preadipocytes implanted into subcutaneous fat area formed cell cluster (Fig. 1B and D). In implanted areas, cell density was much higher than in control mice. Vascular structures were observed in implanted areas to be the same as non-implanted areas. Round cell infiltration surrounded capillaries and degenerated tissues were not found at any areas implanted with 3T3-L1 cells.

The serum concentrations of TNF- $\alpha$ increased gradually after implantation with 3T3-L1 cells into mesenteric area, and these reached $141.6 \pm 30.9 \mathrm{pg} / \mathrm{ml}$ at four weeks. However, the mice which had been injected in subcutaneous area did not show any difference from those of Sham-operated mice (Fig.2A). Body weight during experimental periods did not differ among the mice implanted with 3T3-L1 cells into mesenteric and subcutaneous area, and control (Fig. 2B).

OGTT was analysed at four weeks after implantation (Fig. 3). The glucose concentrations did not show any difference between the mice implanted with 3T3-L1 cells into mesenteric area and control (Fig.3A). However, serum insulin concentrations during the course of glucose loading were apparently higher in the mice implanted into mesenteric area than in control mice (Fig. 3C). The area under the 
A
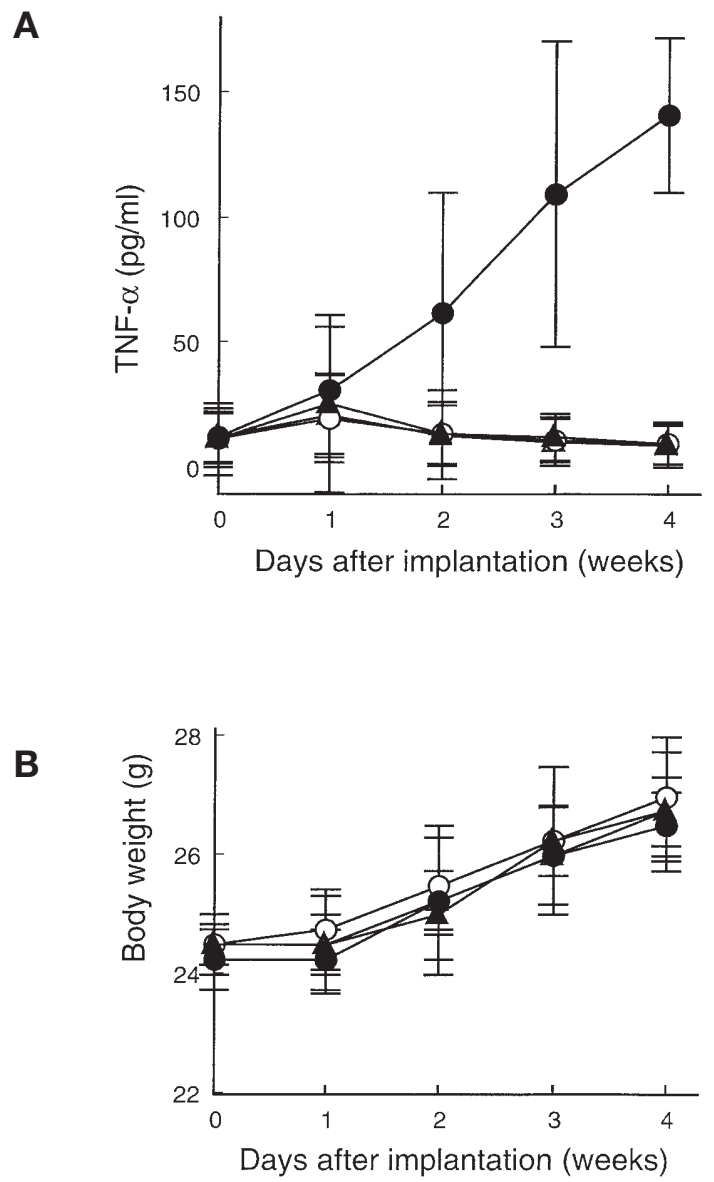

Fig. 2. A Time course of serum TNF- $\alpha$ concentrations in the nude mice implanted with 3T3-L1 cells. Serum concentrations of TNF- $\alpha$ were determined by ELISA. B Time course change of body weight in the nude mice implanted with 3T3-L1 cells. Body weight was measured at every week after implantation. A-B Results are represented as mean and SD. mice injected with 3T3-L1 cells into mesenteric area, $\boldsymbol{\Delta}$ mice injected with 3T3-L1 cells into subcutaneous area, $\bigcirc$ mice injected with PBS alone into mesenteric area, $\triangle$ mice injected with PBS alone into subcutaneous area

curve of insulin concentrations in the mice implanted into mesenteric area was 3.2-fold higher than that in control mice ( $p<0.005$ vs control) (Fig. 3E). Furthermore, the glucose and insulin ratios at 15 min after loading were negatively correlated with the serum concentrations of TNF- $\alpha \quad(p<0.05, \quad r=0.45)$
(Fig. 3F). These results indicate that the insulin sensitivity in mice could be determined by the serum TNF$\alpha$ concentration caused by the secretion from the implanted cells. On the other hand, the serum glucose concentrations after loading were lower in the mice implanted with 3T3-L1 cells into the subcutaneous area than in control mice $(p<0.05)$ (Fig. 3B). Moreover, serum insulin concentrations were also apparently lower in the mice implanted into subcutaneous area than control mice (Fig. 3D). The area under the curve of insulin concentrations in the mice implanted into subcutaneous area was 0.67 -fold lower than that in control mice ( $p<0.05$ vs control) (Fig. 3E). These results suggest that 3T3-L1 cells implanted into subcutaneous area improve glucose metabolism.

We performed RT-PCR analysis for the gene expression of $T N F-\alpha$ in the implanted mesenteric or subcutaneous fat area using specific oligonucleotide primers. As shown in Figure 4A, the contents of TNF- $\alpha$ expression were increased 4.5 -fold in the mesenteric fat implanted with 3T3-L1 cells than those in control mice $(p<0.01$ vs control). However, the TNF- $\alpha$ expression in the subcutaneous fat were 0.3fold lower in the mice implanted into mesenteric area than in control mice $(p<0.01$ vs control) (Fig. 4B). In contrast, the contents of TNF- $\alpha$ expression of mesenteric or subcutaneous area were almost the same in the mice implanted with 3T3-L1 cells into subcutaneous area and control (Fig. 4A and 4B). Moreover, TNF- $\alpha$ expression in femoral muscles did not show any difference among the mice implanted into mesenteric and subcutaneous area, and control (Fig. 4C). These results suggest that the localisation of adipose tissues is important for the cellular function, even if the implanted cells are preadipocyte, not mature adipocytes.

The lipid profile in the serum showed a significant increase in TG concentrations of mice implanted into the mesenteric area, compared to those of mice implanted into subcutaneous area and control mice, although the concentrations of TC and HDL-C did not (Table 1).

We next carried out the correlation analysis of insulin or TNF- $\alpha$ and LPL mass and activity (Fig.5). Post-heparin LPL mass was negatively correlated with serum concentrations of insulin and TNF- $\alpha$ in

Table 1. Effects of 3T3-L1 preadipocyte implantation on body weight and serum lipids

\begin{tabular}{|c|c|c|c|c|}
\hline \multicolumn{5}{|l|}{ Implanted } \\
\hline \multirow{2}{*}{$\begin{array}{l}\text { Area } \\
\text { Cells }\end{array}$} & \multicolumn{2}{|c|}{ Mesenteric area } & \multicolumn{2}{|c|}{ Subcutaneous area } \\
\hline & PBS alone & 3T3-L1 & PBS alone & 3T3-L1 \\
\hline $\mathrm{TC}(\mathrm{mg} / \mathrm{dl})$ & $86 \pm 22$ & $84 \pm 17$ & $88 \pm 20$ & $85 \pm 20$ \\
\hline $\mathrm{TG}(\mathrm{mg} / \mathrm{dl})$ & $25.6 \pm 3.8$ & $46.5 \pm 8.9^{\mathrm{a}}$ & $26.2 \pm 9.2$ & $23.2 \pm 5.4$ \\
\hline $\operatorname{HDL}-\mathrm{C}(\mathrm{mg} / \mathrm{dl})$ & $74 \pm 16$ & $76 \pm 13$ & $75 \pm 18$ & $78 \pm 11$ \\
\hline
\end{tabular}

${ }^{\mathrm{a}} p<0.01$ vs control mice 

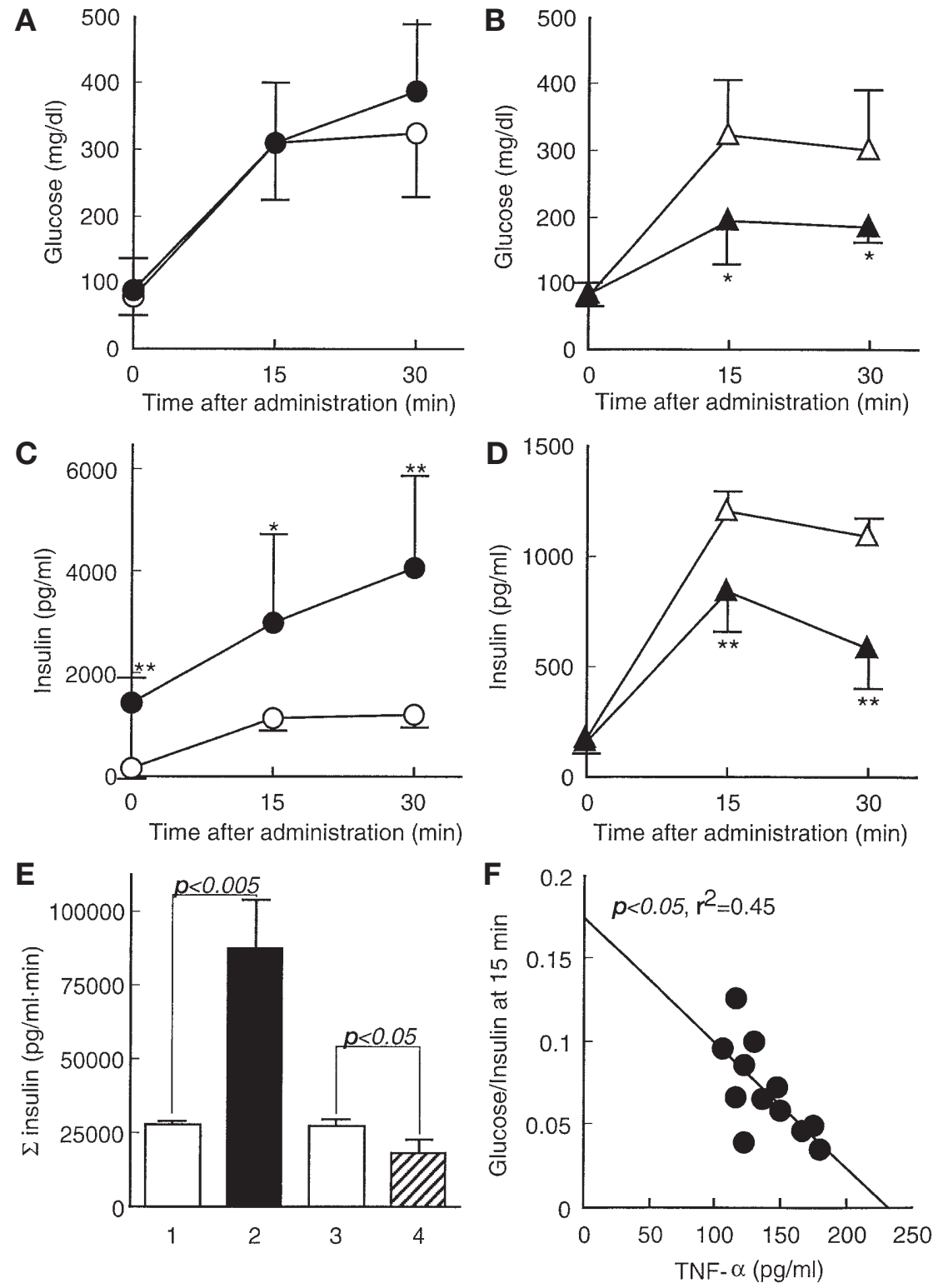

Fig.3. Effects of 3T3-L1 cells implantation into mesenteric and subcutaneous areas on insulin sensitivity. OGTT was done at 4 weeks after oral administration of glucose $(2 \mathrm{mg}$ per $\mathrm{g}$ body weight) and measurement of blood glucose and insulin at 15 and 30 min. A Time course of blood glucose concentrations in the mice implanted into mesenteric area. B Time course of blood glucose concentrations in the mice implanted into subcutaneous area. ${ }^{*} p<0.05$ vs control. C Time course of serum insulin concentrations in the mice implanted into mesenteric area. ${ }^{*} p<0.05$ vs control. $* * p<0.01$ vs control. A, $\mathbf{C}$ mice with 3 T3-L1 cells injected into mesenteric area, $\bigcirc$ control mice. D Time course of serum insulin levels in the mice implanted into subcutaneous area. $* * p<0.01$ vs control. B, D $\boldsymbol{\Delta}$ mice injected into subcutaneous area, with 3T3-L1 cells $\triangle$ control mice. $\mathbf{E}$ The area under the curve of insulin concentrations after glucose loading. Results are given as means $\pm \mathrm{SD}$. Lane 1 ; mice injected into mesenteric area with PBS alone, lane 2; mice injected with into mesenteric area 3T3-L1 cells, lane 3; mice injected into subcutaneous area with PBS alone, lane 4; mice injected with 3T3-L1 cells into subcutaneous area. F Correlation between serum TNF- $\alpha$ concentrations and the glucose and insulin ratios at 15 min after glucose loading in the mice implanted with 3T3-L1 cells into mesenteric area

the mice implanted with 3T3-L1 cells into mesenteric area. Post-heparin LPL activity was also negatively correlated with insulin and TNF- $\alpha$. Major sources of LPL expression were muscle and adipose tissues [16]. Thus, the LPL expression in muscle and adipose tissues seems to be dependent on the serum insulin and TNF- $\alpha$ concentrations regulated by the implanted 3T3-L1 preadipocytes in mice. These results suggest that implanted preadipocytes function affected by the surrounding conditions, and the secreted TNF- $\alpha$ is the key regulator of the metabolic disorders such as hypertriglyceridaemia accompanied with insulin resistance.

The effects of implantation of $h T N F-\alpha$ secreting $\mathrm{CHO}$ cells in nude mice. To investigate the influence of location of adipose tissues for the determination of insulin sensitivity, we established the hTNF- $\alpha$ overexpressing $\mathrm{CHO}$ cell clones because cytokine has been 

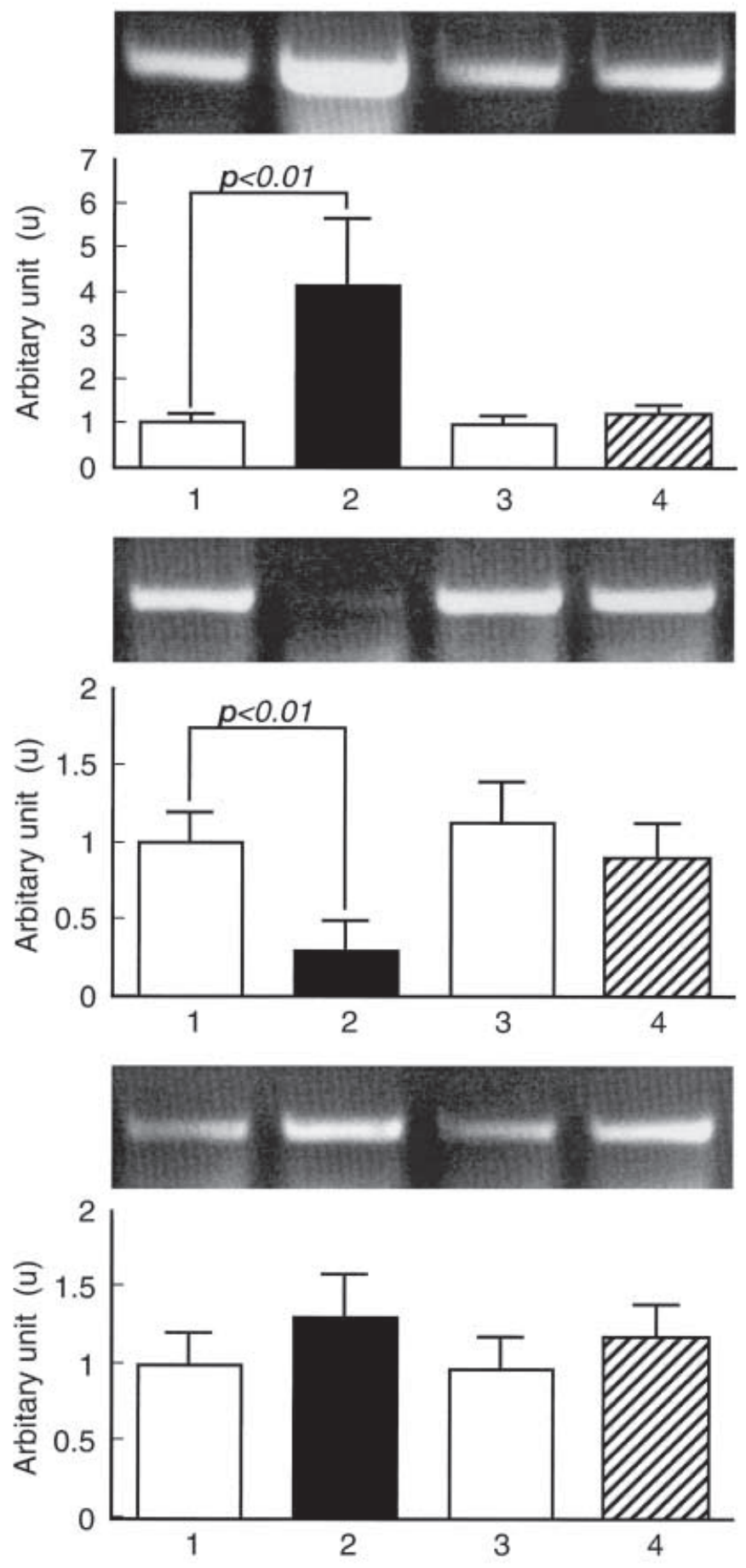

reported to cause insulin resistance in mice using knockout technology. The $\mathrm{CHO}$ cells stably transfected with human TNF- $\alpha$ cDNA showed detectable concentration of the cytokine at $40 \mathrm{ng} / \mathrm{ml}$ in the cultured medium, whereas it was not detectable in the medium with mock-transfected cells. Western blot analysis of conditioned medium from hTNF- $\alpha$ overexpressing $\mathrm{CHO}$ cells using anti-myc antibody as primary antibody revealed that the molecular weight of secreted TNF- $\alpha$ was $23 \mathrm{kDa}$, as expected (data not shown).
Fig. 4. Comparison of TNF- $\alpha$ expressions among the mice implanted into mesenteric or subcutaneous area, and control. A Effect of 3T3-L1 cells implantation into mesenteric area on the TNF- $\alpha$ expression. Lane 1 ; mice injected with PBS alone into mesenteric area, lane 2; mice injected with 3T3-L1 cells into mesenteric area, lane 3; mice injected with PBS alone into subcutaneous area, lane 4; mice injected with 3T3-L1 cells into subcutaneous area. B Effect of 3T3-L1 cells implantation into subcutaneous area on the TNF- $\alpha$ expression. Lane 1; mice injected with PBS alone into mesenteric area, lane 2; mice injected with 3T3-L1 cells into mesenteric area, lane 3; mice injected with PBS alone into subcutaneous area, lane 4; mice injected with 3T3-L1 cells into subcutaneous area. C Comparison of TNF- $\alpha$ expressions in femoral muscles among the mice implanted into mesenteric and subcutaneous area, and control. Lane 1; control mice injected with PBS alone into mesenteric area, lane 2; mice injected with 3T3-L1 cells into mesenteric area, lane 3; mice injected with PBS alone into subcutaneous area, lane 4; mice injected with 3T3-L1 cells into subcutaneous area. (A-C) The images show RT-PCR products of total RNA isolated from femoral muscle. The PCR products were densitometrically analysed and the relative amounts in control mice were set to 1.0, respectively. Results are represented as mean and SD

The hTNF- $\alpha$ overexpressing CHO cells were implanted into the back of nude mice subcutaneously (Fig. 6A). The serum concentrations of hTNF- $\alpha$ increased gradually after implantation into subcutaneous fat area, and these reached to $2345 \pm 2035 \mathrm{pg} /$ $\mathrm{ml}$ at four weeks. However, the control mice injected with $\mathrm{CHO}$ cells transfected with mock vector, did not show any detectable values during the course of observation (Fig.6B). Body weight during experimental periods did not differ between the mice implanted with hTNF- $\alpha$ overexpressing $\mathrm{CHO}$ cells and control (Fig. 6C).

The metabolic markers indicating for insulin sensitivity were analysed at four weeks after implantation (Fig. 7). OGTT did not show any difference of the serum glucose concentrations between the mice implanted with hTNF- $\alpha$ overexpressing cells into subcutaneous area and control (Fig. 7A). However, serum insulin concentrations during the course of glucose loading were apparently higher in the mice implanted with hTNF- $\alpha$ overexpressing cells than in control mice (Fig. 7B). The area under the curve of insulin concentrations in the mice implanted with TNF- $\alpha$ overexpressing cells was twofold higher than that in control mice ( $p<0.001$ vs control) (Fig. 7C). Furthermore, the glucose and insulin ratios at $15 \mathrm{~min}$ after loading were negatively correlated with the serum hTNF- $\alpha$ concentrations (Fig. 7D). These results indicate that the insulin sensitivity in mice is possibly determined by the serum TNF- $\alpha$ concentration caused by the secretion from the implanted cells. Moreover, the glucose and insulin concentrations did not show any difference between the mice implanted with hTNF- $\alpha$ overexpressing cells into subcutaneous or 

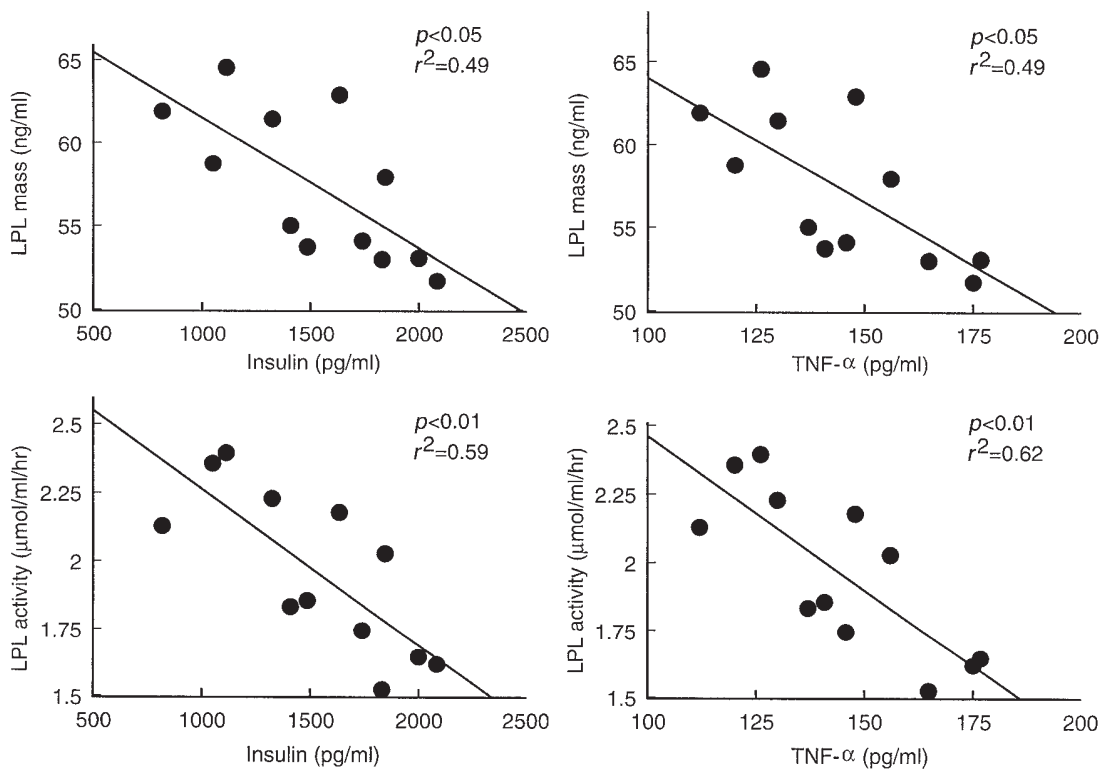

Fig. 5. Correlation between the serum TNF- $\alpha$ or insulin concentration and the LPL mass or activity in the mice implanted with 3T3-L1 cells into mesenteric area. LPL masses and its activities were determined on post-heparin plasma at 4 weeks after implantation
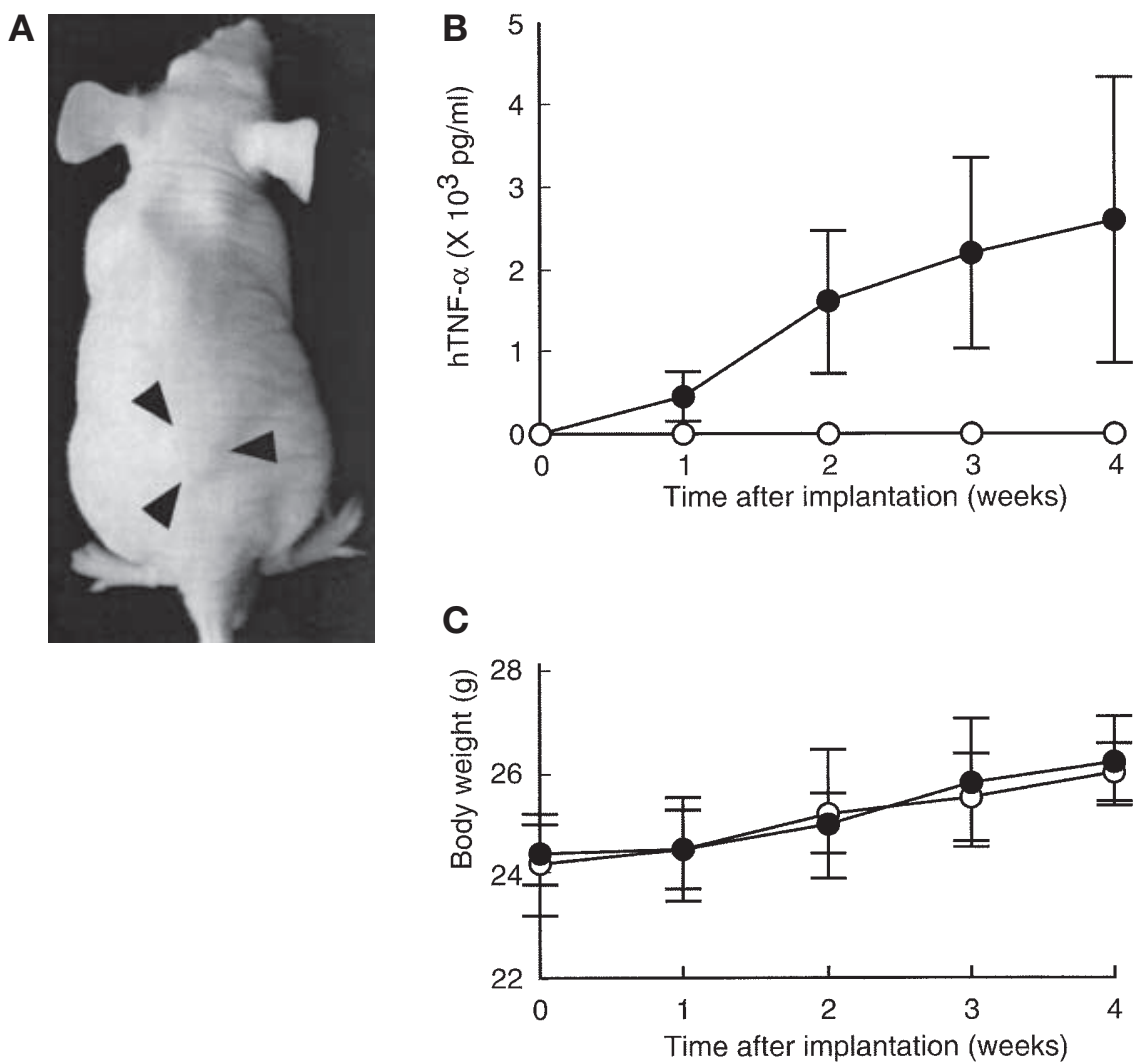

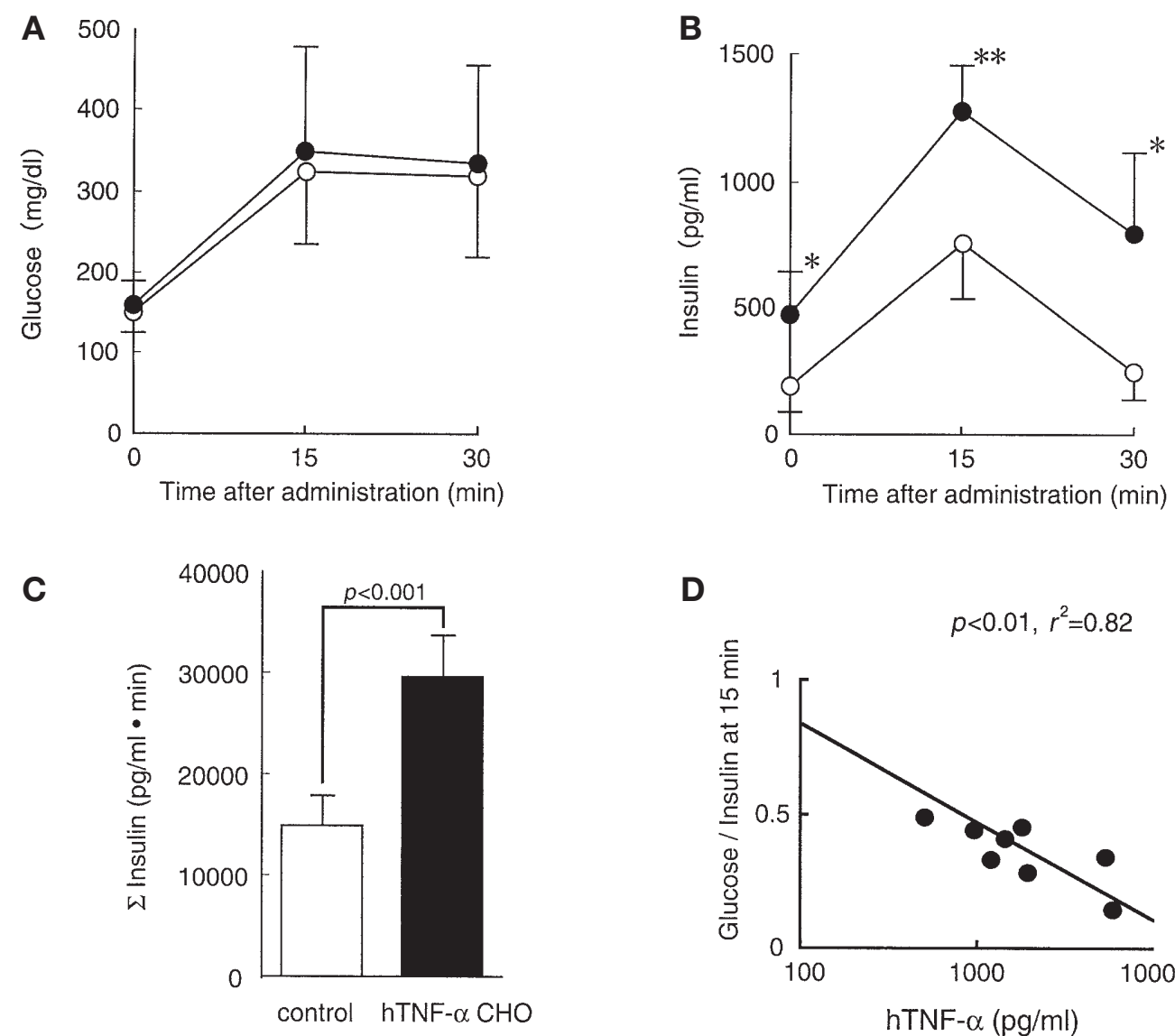

Fig. 7 (A-D). Effect of hTNF- $\alpha$ overexpressing CHO cells implantation into subcutaneous area on insulin sensitivity. OGTT was done as described in Methods. A Time course of blood glucose concentrations. B Time course of serum insulin concentrations. ${ }^{*} p<0.05$ vs control. $* * p<0.01$ vs control. $\mathbf{A}, \mathbf{B}$ mice injected with hTNF- $\alpha$ overexpressing $\mathrm{CHO}$ cells, $\bigcirc$ control mice. C The area under the curve of insulin levels after glucose loading. Results are represented as mean and SD. $\square$ mice injected with hTNF- $\alpha$ overexpressing $\mathrm{CHO}$ cells, $\square$ control mice. D Correlation between the serum hTNF- $\alpha$ levels and the glucose and insulin ratios at 15 minutes after glucose loading in the mice implanted with hTNF- $\alpha$ overexpressing $\mathrm{CHO}$ cells

visceral area (data not shown). These results show that TNF- $\alpha$ regulates the insulin sensitivity in mice even if the producing cells are in subcutaneous area.

\section{Discussion}

In this study, we showed that the implantation of 3T3L1 preadipocytes revealed that the transplanted areas have an important role in the systemic metabolism associated with insulin sensitivity, suggesting that the cellular function is dependent on the surrounding conditions. Furthermore, TNF- $\alpha$ overexpression in the subcutaneous area of mice induces hyperinsulinaemia probably associated with reduced insulin sen-

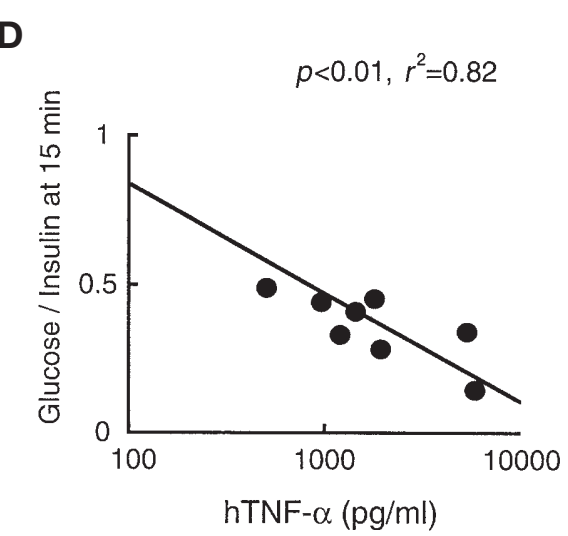

sitivity. The ratio of insulin and glucose concentrations in their sera were negatively correlated with serum TNF- $\alpha$ concentrations.

In culture system, the proliferation rate of preadipocyte derived from subcutaneous fat was faster than that from visceral fat, whereas lipid synthesis from glucose or free fatty acids in visceral adipocytes was more enhanced than that in subcutaneous adipocytes [11]. These results suggest that the visceral and subcutaneous adipocytes might be genetically different. On the other hand, 3T3-L1 preadipocytes in the culture system express leptin at extremely low levels and the expression in culture is not responsive to many physiological agents that have been seen to affect leptin expression in vivo [17]. However, these cells acquire the capacity to express leptin when implanted into subcutaneous area [17]. The results in this study suggest that adipocytes are able to change or modify the cellular function depending on the conditions such as in vivo and in vitro, or subcutaneous and mesenteric areas. These findings together with our results might suggest that adipocytes require the some factors or conditions, present in an in vivo tissue context when the preadipocytes give full play to their own function.

Furthermore, we showed in this study that TNF- $\alpha$ is a key regulator for insulin sensitivity, which accompanies metabolic disorders. TNF- $\alpha$ is known to be important for the regulation of insulin sensitivity in mice 
using knockout technology $[18,19]$. In addition, our results firstly clarified that the location of the source of TNF- $\alpha$ secretion is the pathologically important for the development of insulin resistance and its related disorders. In particular, the expression of LPL is an extremely sensitive marker for the insulin resistance-induced complications. In this context, we have shown that the negative correlation between the serum concentrations of $\mathrm{TNF}-\alpha$ or insulin and the LPL mRNA expression in muscle and subcutaneous fat using the model rats for excessive visceral fat accumulation [10]. These results suggest that the amount of TNF- $\alpha$ secretion in adipocytes is one of the most distinct determinants for the difference of functions observed in subcutaneous and visceral fat tissues.

In summary, this method of adipose cell implantation affects the systemic metabolism associated with insulin sensitivity, probably suggesting that the cellular function is dependent on the surrounding conditions, in addition to their genetic backgrounds. These characteristics of adipocytes might make it possible to establish a new implantation method to improve the metabolic disorders associated with insulin resistance.

Acknowledgements. These studies were supported by grants from the Japanese Ministry of Education, Science, Sports, and Culture. Takahiro Itou is a visiting research fellow from Tokyo Research Laboratories, Pharmaceutical Division, Kowa Company, Ltd.

\section{References}

1. Kissebah AH, Vydelingum N, Murray R et al. (1982) Relation of body fat distribution to metabolic complications of obesity. J Clin Enodocrinol Metab 54: 254-260

2. Tokunaga K, Matsuzawa Y, Ishikawa K (1983) A novel technique for the determination of body fat by computed tomography. Int J Obes 7: 437-745

3. Suzuki R, Watanabe S, Hirai Y et al. (1993) Abdominal wall fat index, estimated by ultrasonography, for assessment of the ratio of visceral fat to subcutaneous fat in the abdomen. Am J Med 95: 309-314

4. Krotkiewski M, Bjorntorp P, Sjostrom L, Smith U (1983) Impact of obesity on metabolism in men and women. Importance of regional adipose tissue distribution. J Clin Invest 72: 1150-1162

5. Kalkhoff RK, Hartz AH, Rupley D, Kissebach AH, Kelber S (1983) Relationship of body fat distribution to blood pressure, carbohydrate tolerance, and plasma lipids in healthy obese women. J Lab Clin Med 102: 621-627

6. Fujioka S, Matsuzawa Y, Tokunaga K, Tarui S (1987) Contribution of intra-abdominal fat accumulation to the impairment of glucose and lipid metabolism in human obesity. Metabolism 36: 54-59

7. Hotamisligil GS, Arner P, Caro JF, Atkinson RL, Spiegelman BM (1995) Increased adipose tissue expression of tumor necrosis factor- $\alpha$ in human obesity and insulin resistance. J Clin Invest 95: 2409-2415

8. Kobayashi J, Tashiro J, Murano S, Morisaki N, Saito Y (1998) Lipoprotein lipase mass and activity in post-heparin plasma from subjects with intra-abdominal visceral fat accumulation. Clin Endocrinol (Oxf) 48: 515-520

9. Taira K, Hikita M, Kobayashi J et al. (1999) Delayed postprandial lipid metabolism in subjects with intra-abdominal visceral fat accumulation. Eur J Clin Invest 29: 301-308

10. Hikita M, Bujo H, Yamazaki K et al. (2000) Differential expression of lipoprotein lipase gene in tissues of the rat model with visceral obesity and postprandial hyperlipidemia. Biochem Biophys Res Commun 22: 423-429

11. Inadera H, Ishikawa Y, Shirai K, Saito Y, Yoshida S (1993) Proliferation and triglyceride synthesizing activities of fibroblast-like cells derived from epidydimal and subcutaneous adipose tissues of rats. Scand J Clin Lab Invest 53: 225-229

12. Shimomura I, Funahashi T, Takahashi M et al. (1996) Enhanced expression of PAI-1 in visceral fat: possible contributor to vascular disease in obesity. Nat Med 2: 800-803

13. Maeda K, Okubo K, Shimomura I, Mizuno K, Matsuzawa Y, Matsubara K (1997) Analysis of an expression profile of genes in the human adipose tissue. Gene 190: 227-235

14. Grarilova O, Marcus-Samuels B, Graham D et al. (2000) Surgical implantation of adipose tissue reverses diabetes in lipodystrophic mice. J Clin Invest 105: 271-278

15. Madrup S, Loftus TM, MacDougald OA, Kuhajda FP, Lane MD (1997) Obese gene expression at in vivo levels by fat pads derived from s.c. implanted 3T3-F442A preadipocytes. Proc Natl Acad Sci USA 94: 4300-4305

16. Semenkovich CF, Chen SH, Wims M, Luo CC, Li WH, Chan L (1989) Lipoprotein lipase and hepatic lipase mRNA tissue specific expression, developmental regulation, and evolution. J Lipid Res 30: 423-431

17. MacDougald OA, Hwang CS, Fan H, Lane MD (1995) Regulated expression of the obese gene product (leptin) in white adipose tissue and 3T3-L1 adipocytes. Proc Natl Acad Sci USA 92: 9034-9037

18. Uysal KT, Wiesbrock SM, Marino MW, Hotamisligil GS (1997) Protection from obesity-induced insulin resistance in mice lacking TNF- $\alpha$ function. Nature 389: 610-614

19. Arbuthnot P, Bralet MP, Thomassin H, Danan JL, Brechot C, Ferry N (1995) Hepatoma cell-specific expression of a retrovirally transferred gene is achieved by alpha-fetoprotein but not insulin like growth factor II regulatory sequences. Hepatology 22: 1788-1796 